\title{
Recent Experimental and Numerical Developments in Semisolid Deformation
}

\author{
ANDRÉ B. PHILLION ${ }^{1,2}$ \\ 1.-School of Engineering, University of British Columbia, Okanagan Campus, Kelowna, BC V1V \\ 1V7, Canada. 2.—e-mail: andre.phillion@ubc.ca
}

Semisolid deformation in metallic alloys has been studied for many years, ${ }^{1}$ both experimentally and through numerical simulations, because mushy zone mechanics plays a key role in the quality of metalcasting processes. For researchers, the topic of semisolid deformation is particularly interesting due to the concomitant phenomena of liquid metal flow, the evolution in fraction solid, and grain coalescence. At the same time, the high temperatures, opacity of the melt, and the strong sensitivity to alloy composition and cooling rates pose strong challenges requiring sustained research effort.

This section of JOM explores recent experimental and numerical developments in semisolid deformation, along with their applications for improving industrial processing. Five diverse articles are presented to highlight current cutting-edge research, from experiments that can directly observe grain rearrangement under various loading modes to models that simulate dendrite deformation.

The first two articles showcase exciting developments in the use of x-ray radiography to directly observe semisolid micromechanics in thin-sample $\mathrm{Al}$ alloy and steel specimens. The article "In situ Investigation of Dendrite Deformation during Upward Solidification of Al-7wt.\%Si" by Reinhart et al. ${ }^{2}$ examines the phenomena of dendrites bending due to gravity, which can precede fragmentation in the case of well-developed secondary arms. The article "Synchrotron Radiography Studies of ShearInduced Dilation in Semisolid Al Alloys and Steels," by Gourlay et al. ${ }^{3}$ focuses on the phenomena of Reynolds dilatancy during shear deformation in alloys with morphologies ranging from equiaxeddendritic to globular.

Andre B. Phillion is the guest editor for the Solidification Committee of the TMS Materials Processing \& Manufacturing Division, and coordinator of the topic Semisolid Deformation: Experimental and Numerical Developments in this issue.
While x-rays can be used to observe local semisolid deformation, the technique known as neutron diffraction is also being used to provide exciting new experimental results to examine structural transitions within the semisolid region. In the article "Deformation of Coherency and Rigidity Temperatures in Al-Cu Alloys using In-Situ Neutron Diffraction during Casting," by Drezet et al., ${ }^{4}$ measurements are reported that quantify the point at which thermally induced deformations start to generate internal stresses in a casting as a function of cooling rates. This knowledge is required for macro-scale casting process simulations.

The final two articles use computational modeling to advance our fundamental knowledge of deformation and defects. The article by Yamaguchi and Beckermann, ${ }^{5}$ "Direct Numerical Simulation of Solid Deformation during Dendritic Solidification," combines a polycrystalline phase-field model with a material point stress analysis to numerically simulate the fully coupled dendritic solidification and elasto-viscoplastic deformation behavior of a pure substance. The results indicate that deformation modifies the crystallographic orientation of a dendrite and the subsequent mushy zone solidification behavior. In "Prediction of Hot Tearing using a Dimensionless Niyama Criterion," by Monroe and Beckermann, ${ }^{6}$ the well-known Niyama criterion is extended to include the effect of applied strain. This new criterion can be easily implemented in industrial casting simulation software to predict both shrinkage porosity and hot tearing susceptibility in a casting process.

Collectively, this series of articles provides new insight into the effects of phenomena at various length-scales on mechanical deformation and failure during solidification. New experimental techniques and new modeling methods are providing exciting results that are key for improving both fundamental understanding of semisolid deformation and industrial casting processes. The reader is also referred to prior JOM issues ${ }^{7,8}$ for other articles on similar themes. 


\section{REFERENCES}

1. D.G. Eskin, Suyitno, and L. Katgerman, Prog. Mater. Sci. 49, 629 (2004).

2. G. Reinhart, H. Nguyen-Thi, N. Mangelinck-Noël, J. Baruchel, and B. Billia, JOM 66 (2014). doi:10.1007/s11837-014-1030-z.

3. C.M. Gourlay, C. O'Sullivan, J. Fonseca, L. Yuan, K.M. Kareh, T. Nagira, and H. Yasuda, JOM 66 (2014). doi:10. 1007/s11837-014-1029-5.
4. J.-M. Drezet, B. Mireux, Z. Szaraz, and T. Pirling, JOM 66 (2014). doi:10.1007/s11837-014-1018-8.

5. M. Yamaguchi and C. Beckermann, JOM 66 (2014). doi:10. 1007/s11837-014-1001-4.

6. C. Monroe and C. Beckermann, JOM 66 (2014). doi:10.1007/ s11837-014-0999-7.

7. A.B. Phillion, JOM 64, 66 (2012).

8. A.B. Phillion, JOM 65, 1094 (2013). 